March 2001

\title{
Comparison of spontaneous with controlled mode of ventilation in tonsillectomy
}

\author{
FA. Khan \\ Aga Khan University, fauzia.khan@aku.edu \\ GA. Memon
}

Follow this and additional works at: https://ecommons.aku.edu/pakistan_fhs_mc_anaesth

Part of the Anesthesia and Analgesia Commons, and the Anesthesiology Commons

\section{Recommended Citation}

Khan, F. A., Memon, G. A. (2001). Comparison of spontaneous with controlled mode of ventilation in tonsillectomy. Paediatric Anaesthesia, 11(2), 185-190.

Available at: https://ecommons.aku.edu/pakistan_fhs_mc_anaesth/204 


\title{
Comparison of spontaneous with controlled mode of ventilation in tonsillectomy
}

\author{
FAUZIA A. KHAN MB, BS, FRCA (UK) AND \\ GHULAM ASGHAR MEMON мB, вS \\ Anaesthesiology Department, The Aga Khan University Hospital, Karachi, Pakistan
}

\begin{abstract}
Summary
Methods: This randomized study compares spontaneous versus controlled ventilation in 60 ASA I and II patients undergoing tonsillectomy as regards haemodynamic stability, recovery characteristics, intra- and immediate postoperative complications and surgical impressions. Results: The patients in the balanced anaesthesia (B) group showed less haemodynamic variability compared to baseline after tracheal intubation, mouth gag application and removal and incision. Two patients had dysrhythmias in the B group compared to six in the spontaneous breathing (S) group. Six patients in the $S$ group had a rise in endtidal carbon dioxide concentration above $7.8 \mathrm{kPa}(60 \mathrm{mmHg})$. Recovery scores were higher in the B group at 10 and 20 min into recovery. The surgical impression of bleeding and jaw relaxation was similar with both groups. The incidence of postoperative nausea and vomiting and agitation was higher in the $S$ group but did not achieve statistical significance.

Conclusions: Use of balanced anaesthesia offered more haemodynamic stability and a rapid recovery.
\end{abstract}

Keywords: anaesthesia: ear, nose, throat; surgery: adenotonsillectomy

\section{Introduction}

Tonsillectomy and adenoidectomy is one of the most common surgical procedures performed in the paediatric age group. It is currently performed under general anaesthesia both with and without the use of nondepolarizing muscle relaxants where the patient is allowed to breathe spontaneously. Both techniques have advantages and disadvantages.

Correspondence to: Dr Fauzia A. Khan, Professor of Anaesthesiology, The Aga Khan University Hospital, Stadium Road, PO Box 3500, Karachi 74800, Pakistan (e-mail: fauzia.khan@aku.edu).
The aim of the present study was to compare the two techniques as regards intraoperative haemodynamic stability, recovery characteristics, intraoperative and immediate postoperative complications, postoperative analgesic requirements in the recovery room and the surgeons impression of the influence of technique on intraoperative bleeding and relaxation at the time of insertion of mouth gag.

\section{Methods}

This study was approved by the Hospital Human Subjects Protection Committee and informed consent was obtained from the parents of the patients. Sixty 
children, ASA physical status I or II, between 3 and 16 years of age and undergoing elective tonsillectomy were studied. Patients with a history of obstructive sleep apnoea were not included. Premedication was not administered. The children were randomly assigned to either group B (balanced anaesthesia technique) or group $S$ (spontaneous anaesthesia technique) by random allocation using a sealed envelope method. Anaesthesia was induced either with oxygen, nitrous oxide and halothane through a mask or $5-6 \mathrm{mg} \cdot \mathrm{kg}^{-1}$ of thiopentone intravenously.

The balanced anaesthesia group $\mathrm{B}$ received injection pethidine $0.8 \mathrm{mg} \cdot \mathrm{kg}^{-1}$ and atracurium 0.6 $\mathrm{mg} \cdot \mathrm{kg}^{-1}$ for muscle relaxation over a standardized period. Maintenance of anaesthesia was with isoflurane $0.8-1 \%$ and oxygen and nitrous oxide 33:66. In group $\mathrm{S}$, suxamethonium $1.5 \mathrm{mg} \cdot \mathrm{kg}^{-1}$ was given to facilitate tracheal intubation and maintenance of anaesthesia was with isoflurane $1.5-3 \%$ and oxygen and nitrous oxide 33:66. Ayer's T-piece circuit with Jackson Rees modification was used in children less than $15 \mathrm{~kg}$ body weight or a Bain circuit with a fresh gas flow of $200 \mathrm{ml} \cdot \mathrm{kg}^{-1}$ in those above $15 \mathrm{~kg}$. Pethidine in this group was given in a dose of 0.8 $\mathrm{mg} \cdot \mathrm{kg}^{-1}$ intramuscularly $5 \mathrm{~min}$ prior to extubation.

A preformed PVC tracheal tube was used in all cases and the size was calculated on the basis of the formula age $/ 4+4.5$ (ID). All patients were extubated in a left lateral head down position.

Monitoring was with a precordial stethoscope, ECG, noninvasive blood pressure, temperature probe, end tidal carbon dioxide and pulse oximeter (Datex Cardiocap II monitor). Respiratory rate was charted every $5 \mathrm{~min}$. The endtidal concentration of inhalational agent was monitored with an infrared analyser (Servo Gas monitor 120, Siemens). All parameters were noted preinduction, every minute for $3 \mathrm{~min}$ after induction, every $1 \mathrm{~min}$ for $5 \mathrm{~min}$ following tracheal intubation, for $2 \mathrm{~min}$ following mouth gag application, following incision and after removal of mouth gag.

The surgeon was asked to grade his impression of jaw relaxation at the time of mouth gag insertion and bleeding from the site of surgery at the end of operation. The same surgeon performed all the operations.

In the recovery room, Steward's Score was charted on arrival, 10, 20, 30 and 60 min post arrival.

\section{Statistical analysis}

Parametric data were compared using one-way analysis of variance. Complications were analysed using either chi-squared or Fisher's exact test. $P<0.05$ was considered statistically significant.

\section{Results}

\section{Demographic data}

The demographic data and the surgical and anaesthetic time of the patients are shown in Table 1. No statistical difference was observed.

\section{Haemodynamic parameters}

Systolic blood pressure (SAP) SAP showed a rise compared to the baseline in the $S$ group only after tracheal intubation, mouth gag application and incision, but the rise was less than $20 \%$ of the baseline in this group. The difference between the two groups was significant at 1,2 and 3 min post intubation and at two minutes after mouth gag insertion (Figure 1).

Diastolic blood pressure (DAP) The DAP changes were the same as above after tracheal intubation, but pressure did not change significantly after mouth gag application or incision.

Mean blood pressure (MAP) The MAP changes mirrored the DAP changes.

Heart rate The heart rate increased in both the groups after tracheal intubation but the difference between groups only became significant three minutes after intubation with the balanced group showing a smaller rise $(21 \%$ in $\mathrm{S}$ versus $18 \%$ in $\mathrm{B}$ group). The rise in heart rate was significantly

Table 1

Demographic data, surgical and anaesthetic time (mean $\pm \mathrm{SD}$ )

\begin{tabular}{lcc}
\hline & Group S & Group B \\
\hline Age (years) & $9.0 \pm 4.4$ & $9.2 \pm 4.8$ \\
Weight (kg) & $29.7 \pm 15.5$ & $34.1 \pm 20.5$ \\
Male:female ratio & $17: 13$ & $21: 9$ \\
Surgical time (min) & $35.3 \pm 12.2$ & $41.2 \pm 13.5$ \\
Anaesthesia duration (min) & $46.3 \pm 15.7$ & $48.6 \pm 14.0$ \\
\hline
\end{tabular}




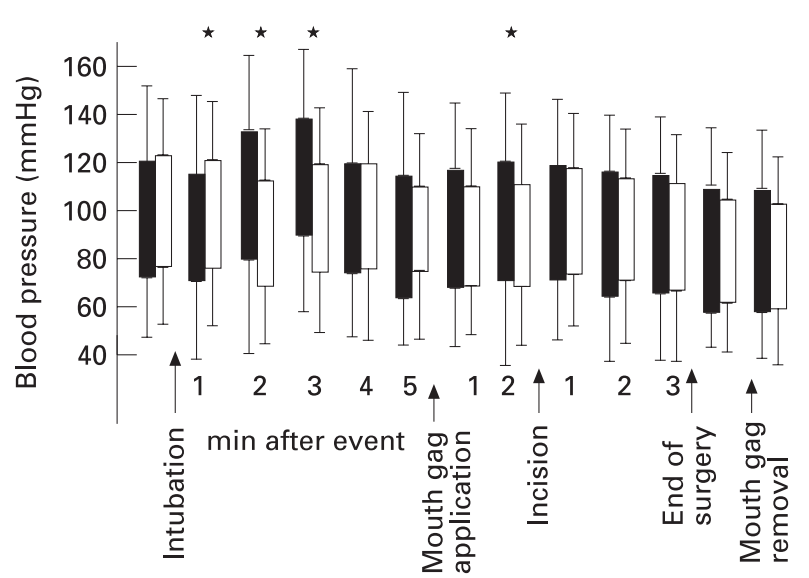

Figure 1

Systolic and diastolic blood pressure changes (mean \pm SD). Group S; $\square$, group B. *Statistical difference between groups, $P<0.05$.

lower in the balanced group 1 min after mouth gag application and at 1,2 and $3 \mathrm{~min}$ after incision (Figure 2).

Dysrhythmias Premature ventricular contractions were seen intraoperatively in five patients in the spontaneous group compared to two in the balanced group. This difference was not significant.

Respiratory rate The preinduction respiratory rate in $\mathrm{S}$ group was $21 \mathrm{~b} \cdot \mathrm{min}^{-1}$ and in $\mathrm{B}$ group was $19 \mathrm{~b} \cdot \mathrm{min}^{-1}$. The mean respiratory rate in group $\mathrm{S}$ varied from 22 to $33 \mathrm{~b} \cdot \mathrm{min}^{-1}$ during the intraoperative period whereas the range was $17-20 \mathrm{~b} \cdot \mathrm{min}^{-1}$ in the B group.

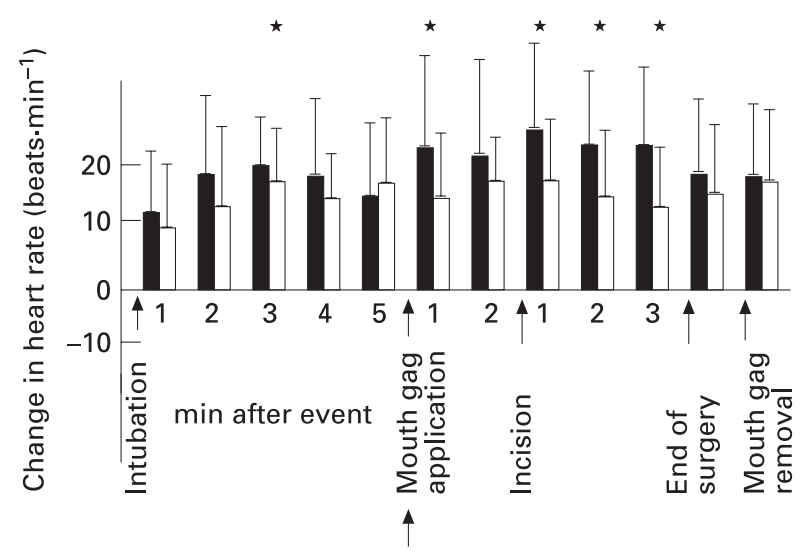

Figure 2

Percentage change in heart rate (mean \pm SD). $\mathbf{0}$, Group S; $\square$, group B. *Statistical difference between groups, $P<0.05$.

\section{Complications}

The complications during induction, maintenance and recovery are listed in Table 2 . The intraoperative mean values of endtidal carbon dioxide ranged from $4.3 \pm 0.5 \quad$ (lowest) to $4.7 \pm 0.7 \mathrm{kPa} \quad$ (highest) $(33.2 \pm 4.2$ to $36.4 \pm 5.5 \mathrm{mmHg})$ in the $\mathrm{B}$ group compared to $4.8 \pm 0.7$ (lowest) to $6 \pm 1.3 \mathrm{kPa}$ $(36.8 \pm 5.4$ to $46.0 \pm 10.2 \mathrm{mmHg})$ in the $\mathrm{S}$ group. The number of patients who had a rise in the $\mathrm{PECO}_{2}$ of more than $7.8 \mathrm{kPa}(60 \mathrm{mmHg})$ intraoperatively was six in the $\mathrm{S}$ group compared to none in the $\mathrm{B}$ group.

None of the patients exhibited any problem during emergence. All patients were followed in the recovery room for $60 \mathrm{~min}$. Steward's scoring done in the recovery room showed lower scores in the spontaneous group and this difference was significant on arrival, 10 and $20 \mathrm{~min}$ in the recovery (Table 3).

\section{Postoperative analgesia}

None of the patients required additional postoperative analgesia in the first $60 \mathrm{~min}$ of recovery.

Table 2

Complications during induction, maintenance and recovery

\begin{tabular}{|c|c|c|c|}
\hline & & Group S & Group B \\
\hline \multicolumn{4}{|c|}{ Induction } \\
\hline \multicolumn{2}{|c|}{ Desaturation $<95 \%$} & 1 & 0 \\
\hline \multicolumn{2}{|c|}{ Bradycardia (rate $<60 \mathrm{~b} \cdot \mathrm{min}^{-1}$ ) } & 0 & 2 \\
\hline \multicolumn{4}{|c|}{ Intraoperative } \\
\hline \multicolumn{2}{|c|}{ Desaturation $<95 \%$} & 1 & 0 \\
\hline \multicolumn{2}{|c|}{ Dysrhythmia } & 5 & 2 \\
\hline \multicolumn{2}{|c|}{$\mathrm{PECO}_{2}>7.8 \mathrm{kPa}(60 \mathrm{mmHg})$} & 6 & $0^{*}$ \\
\hline \multicolumn{2}{|c|}{ Bucking intraoperatively } & 3 & 0 \\
\hline \multicolumn{4}{|l|}{ Recovery room } \\
\hline \multicolumn{2}{|l|}{ PONV } & 4 & 1 \\
\hline \multicolumn{2}{|l|}{ Agitation } & 3 & 1 \\
\hline \multicolumn{4}{|l|}{${ }^{*} P<0.05$} \\
\hline \multicolumn{4}{|c|}{ Table 3} \\
\hline \multicolumn{4}{|c|}{ Steward's scoring in the recovery room } \\
\hline Steward's Score & Group S & Group B & P-value \\
\hline On arrival & $3.3 \pm 0.8$ & $4.2 \pm 1.2$ & $<0.01$ \\
\hline $10 \mathrm{~min}$ & $3.9 \pm 1.1$ & $5.2 \pm 0.9$ & $<0.01$ \\
\hline $20 \mathrm{~min}$ & $4.7 \pm 1.2$ & $5.6 \pm 0.8$ & $<0.01$ \\
\hline $30 \mathrm{~min}$ & $5.5 \pm 1.1$ & $5.8 \pm 0.5$ & NS \\
\hline $60 \mathrm{~min}$ & $5.7 \pm 1.2$ & $5.9 \pm 0.4$ & NS \\
\hline
\end{tabular}


Table 4

Surgical impressions

\begin{tabular}{lcc}
\hline & Group S & Group B \\
\hline Relaxation on mouth gag application & & \\
$\quad$ Poor & 4 & 1 \\
Fair & 6 & 0 \\
Good & 14 & 21 \\
Excellent & 6 & 8 \\
Surgical impressions of bleeding & & \\
$\quad$ Minimal & 25 & 26 \\
$\quad$ Moderate & 5 & 4 \\
$\quad$ Severe & 0 & 0 \\
\hline
\end{tabular}

\section{Surgical impressions}

No difference was observed between the groups in the surgical impressions of jaw relaxation and bleeding (Table 4).

\section{Discussion}

One of the first references in literature regarding tonsillectomy surgery was 3000 years ago (1). There are currently several indications for tonsillectomy with or without adenoidectomy. These include both definitive indications such as obstructive sleep apnoea, speech abnormalities, facial growth abnormalities and eating and swallowing disorders. Relative indications include recurrent throat infections and streptococcus carrier state (2).

Maintenance of stable haemodynamics together with smooth nonemetic painfree recovery and rapid return of airway reflexes are considered desirable features for tonsillectomy anaesthesia. The above goals are partially achievable both with spontaneous or controlled ventilation with short acting muscle relaxants such as atracurium and mivacurium. Positive pressure ventilation provides good muscle relaxation, lesser requirements of volatile anaesthetic agent, and lesser chances of patient movement with early return of airway reflexes. On the other hand spontaneous ventilation has an inherent safety if disconnection occurs, anticholinesterases are avoided and recovery is smoother with theoretically lesser chances of rebleed. The majority of the studies in patients undergoing tonsillectomy surgery have concentrated on methods of providing analgesia (3-5). There is a lack of studies for rationalizing the technique.
The intraoperative haemodynamic responses in the $S$ group patients in our study were exaggerated compared to the intermittent positive-pressure ventilation (IPPV) group. This was not surprising since analgesic in the IPPV group was administered at the time of induction in comparison to $S$ group where analgesia was given intramuscularly towards the end of surgery and intraoperative analgesia was provided by nitrous oxide and isoflurane. Pethidine was given intramuscularly towards the end of the procedure to provide mainly postoperative analgesia. Pethidine was avoided early in the $S$ group because of the additive depressant effect on the respiratory parameters. Earlier use of pethidine at the time of induction in this group would theoretically result in delay in establishing spontaneous ventilation, a higher number of patients with $\mathrm{PECO}_{2}$ more than $7.8 \mathrm{kPa}(60 \mathrm{mmHg})$ and a greater chance of dysrhythmias.

Isoflurane was used as the inhalational agent in both groups although in differing concentrations. It is especially useful in ENT surgery due to its safety in the presence of exogenous catecholamines, rapid awakening and minimal postoperative nausea and vomiting $(6,7)$. Our results indicate that isoflurane in $1.5-3 \%$ concentration and $66 \%$ of nitrous oxide was not able to provide equipotent analgesia comparable with $0.8 \mathrm{mg} \cdot \mathrm{kg}^{-1}$ pethidine during the intraoperative period. However, it needs to be pointed out that the haemodynamic variability was limited to approximately $20 \%$ of the baseline even in the spontaneous group, a variation which is acceptable.

Valentin et al. studied the endtidal concentration specifically and found that 40 out of 100 children in their study had values greater than 7\% (8). Only six patients in the $S$ group in our study showed a rise in endtidal carbon dioxide concentration of more than $7.8 \mathrm{kPa}(60 \mathrm{mmHg})$. The former had used the Bain's circuit for all the patients whereas we used the modified T-piece circuit in patients less than $15 \mathrm{~kg}$ which may account for the difference seen. Only two patients in the B group in our study had premature ventricular dysrhythmia compared to five patients in the $S$ group. None of these patients who exhibited dysrhythmias had endtidal carbon dioxide concentration more than $7.8 \mathrm{kPa}(60 \mathrm{mmHg})$. This was much lower than the $72 \%$ figure quoted by Sigurdsson and Lindahl in patients undergoing halothane anaesthesia and $32 \%$ during enflurane anaesthesia 
for adenoidectomy (9). Stove reported only two short episodes of sinus dysrhythmia with positive pressure ventilation and no dysrhythmia with spontaneous ventilation (10). Two patients in group B had heart rate falling to less than 60 beats $\mathrm{min}^{-1}$ at the time of induction. This did not require any treatment. In ENT surgery, the dysrhythmias can be mediated by a variety of vagal reflexes, this could be the possible cause in our patients who had dysrhythmias (11). The lower incidence of dysrhythmias in our study was probably due to the use of isoflurane.

In two patients in the $\mathrm{S}$ group, the oxygen saturation fell to $<95 \%$, one during induction and one during the maintenance period, but this was corrected by increasing the $\mathrm{FIO}_{2}$ to $50 \%$ and did not require any further management. This was most probably related to rapid shallow breathing.

We encountered no problem with the IPPV group in our study related to the use of muscle relaxant atracurium, both intraoperatively or in the recovery room.

There is existing controversy regarding deep versus awake extubation (12). There is a lack of controlled studies demonstrating a superiority of either method. Deep extubation with a patient in a left lateral and head down position is preferred by some inspite of blood or secretions which may be present in the pharynx in tonsillectomy anaesthesia. This is justified because of the quality of recovery which is smooth and undisturbed with lesser chances of oozing from the operative site and a lesser incidence of postoperative haemorrhage. This was the method used in our S group patients. IPPV on the other hand results in a more rapid but stormy recovery. Patel et al. (13) studied the incidence of airway related complications in two groups of children undergoing tonsillectomy or strabismus surgery where one group was extubated light and another deep. No difference was seen between the groups. In our study again there was no statistical difference seen in either group as regards complications at the time of emergence.

The reported incidence of posttonsillectomy complications varies. Colclasure and Graham reviewed 3340 cases and found a $1.4 \%$ incidence of major complication (14). This included primary or delayed haemorrhage and anaesthetic complications such as severe nausea and dehydration. A national survey based in the USA, including 1.3 million tonsillectomies, found the incidence of posttonsillectomy bleeding as $1.2 \%$ and a mortality rate of $0.002 \%$ (15). In our study, no immediate airway complication was observed in either group but recovery scores were better with lower Steward score (16) in the first 20 min of anaesthesia in the B group. Parents were allowed in the recovery room for both groups.

The incidence of postoperative nausea and vomiting, although slightly higher in our S group, did not achieve statistical significance. The incidence of posttonsillectomy emesis has been shown to be approximately $40-70 \%$ (17), it was $13 \%$ in S group and $3 \%$ in the $\mathrm{B}$ group in our patients. The lower incidence in the immediate recovery in our study may be due to the use of isoflurane. Van den Berg also found a low incidence of postoperative nausea and vomiting in the recovery period (7). A larger series of patients may be required to show any real difference in postoperative nausea and vomiting between the two techniques.

The choice of technique did not seem to affect the rating given by the surgeon to jaw relaxation and surgical impression of bleeding. None of our patients had a posttonsillectomy bleed or required intraoperative blood transfusion.

In conclusion, no difference was observed between the two techniques regarding intraoperative or immediate postoperative complications apart from increase in endtidal carbon dioxide concentration to more than $7.8 \mathrm{kPa}(60 \mathrm{mmHg})$ in six patients in the $\mathrm{S}$ group during anaesthesia. IPPV using atracurium and low dose isoflurane anaesthesia did result in less variation in intraoperative haemodynamic parameters and better recovery characteristics in the first $20 \mathrm{~min}$ following anaesthesia.

\section{Acknowledgement}

We would like to thank Ms Bilquis Amyn Fazli for her secretarial assistance in the preparation of the manuscript.

\section{References}

1 Kearns DB, Pransky SM, Seid AB. Current concepts in paediatric adenotonsillar disease. Ear Nose Throat J 1991; 70: 15-19.

2 Deutsch ES. Tonsillectomy and adenoidectomy. Changing indications. Ped Clin North Am 1996; 43: 1319-1338. 
3 Jebeles JA, Reilly JS, Gutierrez JF et al. The effect of preincisional infiltration of tonsils with bupivacaine on the pain following tonsillectomy under general anesthesia. Pain 1991; 47: 305-308.

4 Van den Berg AA, Honjol NM, Rama Prabhu NV et al. Analgesics and ENT surgery. Br J Clin Pharmacol 1994; 38: 533-543.

5 Rorarius MG, Baer GA, Siirtola M et al. Effect of intravenous diclofenac or indomethacin on the emergence from anaesthesia for tonsillectomy. Acta Anaesthesiol Scand 1993; 37: 616621.

6 Jones RM. Clinical comparisons of inhalational anaesthetic agents. Br J Anaesth 1984; 54: 575-695.

7 Van den Berg AA, Savva D, Honjol NM et al. Comparison of total intravenous balanced inhalational and combined intravenous-inhalational anaesthesia for tympanoplasty, septorhinoplasty and adenotonsillectomy. Anaesth Intens Care 1995; 23: 574-582.

8 Valentin N, Lamholt B, Thorup M. Halothane anaesthesia with spontaneous respiration for tonsillectomy in children. Acta Anaesthesiol Scand 1982; 26: 53-55.

9 Sigurdsson GH, Carlsson C, Lindahl S et al. Cardiac arrhythmias in non-intubated children during adenoidectomy. A comparison between enflurane and halothane anaesthesia. Acta Anaesthesiol Scand 1983; 27: 75-80.
10 Stow PJ, White JB. Anaesthesia for paediatric tonsillectomy. Comparison of spontaneous ventilation and intermittent positive pressure ventilation. Br J Anaesth 1987; 59: 419-423.

11 Wood PR, Foley MA, Lawler PG. Vagal reflexes and anaesthesia. Br J Hosp Med 1990; 44: 137-139.

12 Dillon FX. Safety considerations for otolaryngologic surgery in anaesthesia for otolaryngologic and head and neck surgery. Anesth Clin North Am 1993; 11: 637-649.

13 Patel RI, Hannallah RS, Norden J et al. Emergence airway complications in children: a comparison of tracheal extubation in awake and deeply anesthetized patients. Anesth Analg 1991; 73: 266-270.

14 Colclasure JB, Graham SS. Complications of out-patient tonsillectomy and adenoidectomy. A review of 3,340 cases. Ear Nose Throat J 1990; 69: 155-160.

15 Pratt LW, Gallagher RA. Tonsillectomy and adenoidectomy. Incidence and mortality. Arch Otolaryngol Head Neck Surg 1979; 87: 159-166.

16 Steward DJ. A simplified scoring system for the postoperative recovery room. Can Anaesth Soc J 1975; 22: 111-113.

17 Ved SA, Walden TL, Montana Lea DE et al. Vomiting and recovery after out-patient tonsillectomy and adenoidectomy in children. Anesthesiology 1996; 85: 4-10.

Accepted 1 August 2000 